\title{
Clinicopathological analysis of appendiceal mucinous tumors: A single-center experience
}

\author{
Arif Emre, Mehmet Sertkaya, Illhami Taner Kale
}

\section{ABSTRACT}

\section{Cite this paper as:}

Emre A, Sertkaya M, Kale iT. Clinicopathological analysis of appendiceal mucinous tumors: A single-center study. Turk J Surg 2017; 33: 274-278.

Department of General Surgery, Kahramanmaraş Sütçü İmam University School of Medicine, Kahramanmaraş, Turkey

This study was presented at the XIII. National Hepato Gastroenterology Congress, 27 April-01 May 2016, Antalya, Turkey.

Address for Correspondence Arif Emre e-mail:dr.arifemre@gmail.com

Received: 05.04 .2016 Accepted: 25.05.2016

OCopyright 2017 by Turkish Surgical Association
Objective: Appendiceal mucinous tumors can be encountered in four different types. The clinical approach varies according to these types and the severity of the present disease. We aimed to share clinical, radiological, and pathological features and surgical options of the patients diagnosed with mucinous tumors at our center.

Material and Methods: Between August 2009 and March 2016, 757 patients underwent appendectomy for presumed diagnosis of acute appendicitis at the Department of Surgery, Kahramanmaraş Sütçü İmam University School of Medicine, Kahramanmaraș, Turkey. Among them, demographic, clinical, and histopathological characteristics of patients who diagnosed with appendiceal mucinous tumors were retrospectively analyzed. This study was approved by our faculty's human ethics committee.

Results: Incidence of mucinous tumor was $1.71 \%$. Mean age of a total of 13 cases including 6 women and 7 men was $52.4 \pm 21.6$ years (Range: $25-83$ years). On preoperative diagnosis, acute appendicitis was detected in 8 patients, perforated appendicitis and periappendiceal abscess in two patients, and suspicious cecal mass in two patients. One patient had an operation for uterine leiomyoma. On histopathological examination, four patients were diagnosed with simple mucinous cyst, four with mucinous cystadenoma, three with mucosal hyperplasia, and two with mucinous cystadenocarcinoma. Mean duration of hospital stay was $5.1 \pm 4.7$ days. One patient died from septic shock on first day, one from respiratory failure on 14th day, and one from cardiac arrest on 20th day. The average follow-up duration for the other 10 patients was 44 months (ranging from 1 to 78 months). No recurrence or death occurred in these patients over the course of follow-up.

Conclusion: Intraoperative clinical diagnosis of appendiceal mucinous tumors is rarely seen. Close histopathological and cytological examination of the specimen is required to separate malignant tumors from benign ones. The treatment varies depending on different types and the severity of the disease.

Keywords: Appendiceal mucinous tumors, cystadenoma, cystadenocarcinoma, mucocele, mucosal hyperplasia

\section{INTRODUCTION}

Appendiceal mucocele is a pathological process occurring due to mucosal inflammatory or neoplastic diseases that result in the formation of an enlarged appendix and thinned appendicular wall caused by abnormal accumulation of mucus in the appendicular lumen, depending on any obstructive etiologic agent. It is at least two times more common in women than in men, and is only observed in $0.2 \%-0.7 \%$ of all appendectomy specimens (1-3). Although it is one of the most common primary epithelial tumors in the appendix, it is a rare clinical condition compared with other pathologies. This disease has unpredictable biological behavior in consideration of its outcomes. There is a large body of literature showing that mucocele is an important pathological condition as spontaneous or iatrogenic ruptures lead to pseudomyxoma peritoneum (PP) syndrome, of which a complete treatment algorithm has not been established so far. Four different types of formations widely accepted in the literature are retention cysts, mucosal hyperplasia, cystadenoma, and cystadenocarcinoma. Although clinical presentation of mucocele is nonspecific, it is incidentally detected during appendectomies, which are mostly performed for acute appendicitis. Cystadenoma and cystadenocarcinoma have more clinical significance because spontaneous or iatrogenic rupture of these can lead to PP syndrome. Opting for open laparotomy in the presence of a mucocele detected during laparoscopic procedures is extremely important to ensure that all spaces in the peritoneal cavity are explored and that the appendix wall remains intact and does not lead to PP syndrome, which is considered to be malignant and develops as a result of rupture (4). Understanding the clinical and pathological profile of patients with appendiceal mucocele can help the clinicians in better diagnosis and management of this rare condition. Therefore, in this retrospective study, besides the clinical, radiological, and pathological profile of the patients with mucocele, we also aimed to focus on the surgical management of appendiceal mucinous tumors according to different types.

\section{MATERIAL AND METHODS}

Data for this study were obtained through retrospective analysis of files of patients who underwent appendectomy at the Department of Surgery, Kahramanmaraş Sütçü İmam University School of Medi- 
Table 1. Preoperative characteristics of the patients

\begin{tabular}{|llllllll} 
& & & & & & \\
Age & Sex & Admittion type & Main complaint & USG/CT/MRI & WBC & CRP & Presumed diagnosis \\
\hline 83 & M & Emergency & Abdominal pain & $-/-/-$ & Normal & Elevated & Acute appendicitis \\
\hline 34 & M & Emergency & Abdominal pain & $+/+/-$ & Normal & Normal & Acute appendicitis \\
\hline 72 & F & Electively & Abdominal pain & $-/-/+$ & Normal & Non available & Incidentally \\
\hline 80 & M & Emergency & Abdominal pain & $-/-/-$ & Elevated & Elevated & Acute appendicitis \\
\hline 61 & F & Emergency & Abdominal pain & $+/+/-$ & Elevated & Elevated & Perforated appendicitis \\
\hline 33 & M & Emergency & Abdominal pain & $-/-/-$ & Non available & Non available & Acute appendicitis \\
\hline 49 & F & Emergency & Abdominal pain & $-/-/-$ & Normal & Elevated & Acute appendicitis \\
\hline 81 & F & Emergency & Abdominal pain & $-/-/-$ & Normal & Elevated & Perforated appendicitis \\
\hline 60 & M & Electively & Abdominal mass & $-/+/-$ & Normal & Non available & Abdominal mass \\
\hline 41 & M & Emergency & Rectal bleeding & $-/+/-$ & Normal & Non available & Abdominal mass \\
\hline 37 & F & Emergency & Abdominal pain & $-/-/-$ & Elevated & Elevated & Acute appendicitis \\
\hline 25 & F & Emergency & Abdominal pain & $-/-/-$ & Elevated & Non available & Acute appendicitis \\
\hline 25 & M & Emergency & Abdominal pain & $-/-/-$ & Elevated & Non available & Acute appendicitis \\
\hline
\end{tabular}

F: female; M: male; WBC: white blood cells; CRP: C-reactive protein; USG: ultrasonography; CT: computed tomography; MR: magnetic resonance imagining

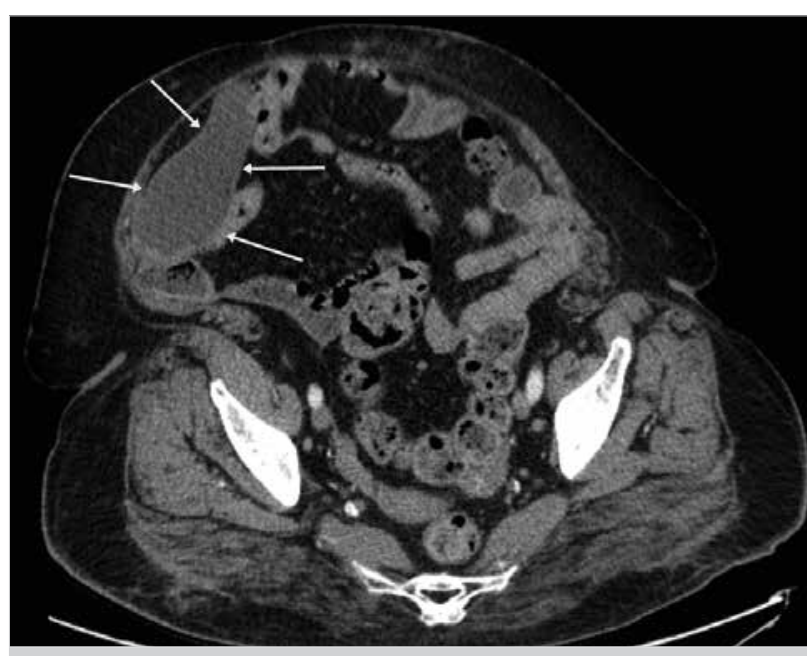

Figure 1. Computed tomography image of a giant mucocele

cine, Kahramanmaraş, Turkey. On April 20th, 2016, ethics committee approval was obtained from our faculty for this study. A total of 13 patients whose histopathological reports were compatible with primary appendiceal mucinous tumor from among 757 appendectomy cases between August 2009 and March 2016 were included in the study. Demographic data including patients age, gender, preoperative complaints, radiological assessments, inflammatory parameters, surgical procedure, histopathological examination of specimens, associated gynecological and colorectal pathologies, duration of hospitalization, information regarding recurrence or death, and records of causes of death were analyzed.

\section{RESULTS}

Mucinous tumor was detected in 13 of a total of 757 appendectomy specimens. Incidence of mucinous tumor was $1.71 \%$. Mean age of a total of 13 cases including six women (46\%) and seven men (54\%) was $52.4 \pm 21.6$ years (Range: $25-83$ years). Eleven patients were first admitted to emergency service and the other two electively presented at the outpatient clinic. Eleven patients (84.5\%) complained of abdominal pain as the most common symptom; abdominal mass was detected in one patient $(7.75 \%)$ and lower gastrointestinal system bleeding was seen in one patient (7.75\%). Computed tomography (CT) was performed in two patients (Figure 1), magnetic resonance imaging (MRI) in one patient, and CT and ultrasonography (USG) in two patients. Although data on WBC count of one patient were not retrieved from the medical records, leukocytosis was present in five (42\%) and normocytosis in seven (58\%) of 12 patients. Data on CRP level of six patients were not extracted from the medical records, and there was an increase in this value in six ( $86 \%$ ) out of the remaining seven patients.

In preoperative diagnosis, acute appendicitis was detected in eight patients, perforated appendicitis and periappendiceal abscess in two patients, and suspicious cecal mass in two patients. One patient underwent an operation for uterine leiomyoma (Table 1). Periappendiceal mucin deposits were detected in four patients intraoperatively. Right hemicolectomy was performed in the same session for two of these patients whose histopathological examination was indicated cystadenocarcinoma and for other two in the early period after appendectomy. Partial cecum resection together with appendectomy was performed for one patient with giant benign mucinous cystadenoma depending on frozen section examination (Figure 2). Seven patients underwent wide mesoappendix excision along with appendectomy. On pathological examination, epithelial cells were identified in the mucin deposits of only one patient out of four patients in which periappendiceal mucin deposits were detected. Except for a patient who had been operated for uterine leiomyoma with a diameter of $10 \mathrm{~cm}$ and whose appendiceal mucocele was incidentally detected during surgery, any accompanying ovarian or colorectal pathology was not detected in any other patients. Macroscopic examination of 12 patients' appendix from pathology records showed that average diameter of the appendix was $23.5 \mathrm{~mm}$ (ranging from 
Table 2. Postoperative characteristics of the patients

\begin{tabular}{|c|c|c|c|c|c|c|c|c|c|}
\hline $\begin{array}{l}\text { Type of } \\
\text { Surgery }\end{array}$ & $\begin{array}{l}\text { Appendix } \\
\text { length/size } \\
(\mathrm{mm})\end{array}$ & $\begin{array}{l}\text { Extraappendiceal } \\
\text { mucine, epithelial } \\
\text { cells }\end{array}$ & $\begin{array}{l}\text { Associated } \\
\text { pathology }\end{array}$ & $\begin{array}{l}\text { Pathologic } \\
\text { examination }\end{array}$ & $\begin{array}{l}\text { Hospital } \\
\text { stay } \\
\text { (day) }\end{array}$ & $\begin{array}{l}\text { Follow-up } \\
\text { (day, month) }\end{array}$ & Recurrence & Mortality & $\begin{array}{l}\text { Cause of } \\
\text { mortality }\end{array}$ \\
\hline Appendectomy & $80 / 10$ & & & Muc. cyst & 14 & $14 d$ & Died & Yes & $\begin{array}{l}\text { Respiratory } \\
\text { failure }\end{array}$ \\
\hline Appendectomy & $40 / 15$ & & & Muc. cyst & 1 & $50 \mathrm{mo}$ & No & & \\
\hline Appendectomy & $35 / 30$ & & $\begin{array}{l}\text { Uterine } \\
\text { leiomyoma }\end{array}$ & Muc. cyst & 3 & $51 \mathrm{mo}$ & No & & \\
\hline Appendectomy & $50 / 15$ & & & Muc. cyst & 11 & $20 d$ & Died & Yes & $\begin{array}{l}\text { Cardiac } \\
\text { failure }\end{array}$ \\
\hline $\begin{array}{l}\text { Appendectomy+ } \\
\text { partial cecal resection }\end{array}$ & $140 / 50$ & & & $\begin{array}{l}\text { Muc. } \\
\text { cystadenoma }\end{array}$ & 5 & $20 d$ & No & & \\
\hline Appendectomy & $60 / 30$ & & & $\begin{array}{l}\text { Muc. } \\
\text { cystadenoma }\end{array}$ & 3 & $50 d$ & No & & \\
\hline Right hemicolectomy & $40 / 15$ & $\begin{array}{l}\text { Mucine (+), } \\
\text { epithelial cells (-) }\end{array}$ & & $\begin{array}{l}\text { Muc. } \\
\text { cystadenoma }\end{array}$ & 13 & $6 \mathrm{mo}$ & No & & \\
\hline Right hemicolectomy & $50 / 10$ & $\begin{array}{l}\text { Mucine (+), } \\
\text { epithelial cells (-) }\end{array}$ & & $\begin{array}{l}\text { Muc. } \\
\text { cystadenoma }\end{array}$ & 1 & $1 d$ & Died & Yes & $\begin{array}{l}\text { Septic } \\
\text { shock }\end{array}$ \\
\hline Right hemicolectomy & $120 / 30$ & $\begin{array}{l}\text { Mucine (+), } \\
\text { epithelial cells (+) }\end{array}$ & & $\begin{array}{l}\text { Muc. } \\
\text { cystadenocar- } \\
\text { cinoma }\end{array}$ & 4 & $49 \mathrm{mo}$ & No & & \\
\hline Right hemicolectomy & & $\begin{array}{l}\text { Mucine (+), } \\
\text { epithelial cells (-) }\end{array}$ & & $\begin{array}{l}\text { Muc. } \\
\text { cystadenocar- } \\
\text { cinoma }\end{array}$ & 8 & $50 \mathrm{mo}$ & No & & \\
\hline Appendectomy & $40 / 5$ & & & $\begin{array}{l}\text { Mucosal } \\
\text { hyperplasia }\end{array}$ & 1 & $78 \mathrm{mo}$ & No & & \\
\hline Appendectomy & $60 / 5$ & & & $\begin{array}{l}\text { Mucosal } \\
\text { hyperplasia }\end{array}$ & 2 & $76 \mathrm{mo}$ & No & & \\
\hline Appendectomy & $70 / 10$ & & & $\begin{array}{l}\text { Mucosal } \\
\text { hyperplasia }\end{array}$ & 1 & $78 \mathrm{mo}$ & No & & \\
\hline
\end{tabular}

Muc: mucinous; d: day; mo: month; mm: milimeter

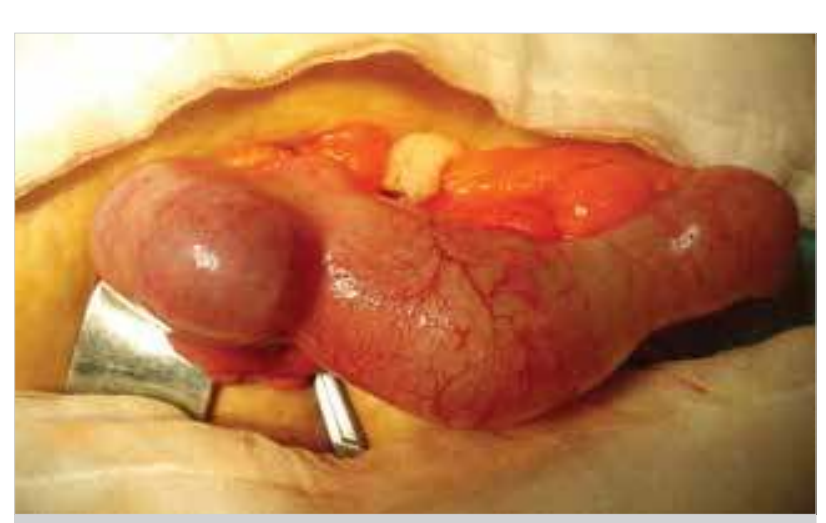

Figure 2. Perioperative view of a giant mucocele

$5 \mathrm{~mm}$ to $50 \mathrm{~mm}$ ) and average length was $62 \mathrm{~mm}$ (ranging from $35 \mathrm{~mm}$ to $140 \mathrm{~mm}$ ). Information on the average length and diameter of one patient's appendix was not obtained from the pathological records. As a result of histopathological examinations, four patients were diagnosed with simple mucinous cyst, four with mucinous cystadenoma, three with mucosal hyperplasia, and two with mucinous cystadenocarcinoma. Average length of hospital stay was 5.2 days. One patient died cardiac arrest on days 1, 14 and 20, respectively. The mean follow-up duration for the other 10 patients was $13.21 \pm 9.27$ days (Range: 20-2340 days). No recurrence occurred in these 10 patients over the course of follow-up (Table 2).

\section{DISCUSSION}

The mucocele of the appendix was first described as a pathological entity in 1842 by Karel Rokitansky (5). It is characterized by the obstructive dilatation of the organ lumen with accumulation of mucoid material. Although being one of the most common primary epithelial tumors in the appendix, it is a rare clinical condition compared with other pathologies. It is found in $0.2 \%$ to $0.7 \%$ of the appendectomies $(6,7)$. In our study, the incidence of mucinous tumors was much higher than that reported in the literature, with a rate of $1.71 \%$.

Appendiceal mucinous tumors consist of a rare disease that is generally diagnosed clinically during the operation. However, closer histopathological and cytological examination of the specimen may be required to distinguish malignant tumors from benign ones (8). There are four different types of formations that cause the mucocele of the appendix according to the World Health Organization: simple mucocele or retention mucocele, mucosal hyperplasia (5\%-25\%), mucinous 
cystadenoma (63\%-84\%), mucinous cystadenocarcinoma (11\%-20\%) (7-10). Simple mucocele is a condition characterized by the presence of normal epithelial cells and the accumulation of mucinous material in the lumen depending on the occlusion of the appendiceal lumen in the presence of a fecaloid or other obstructive etiological factors. Dilation is expected to be up to $1 \mathrm{~cm}$. However, the diameter is usually greater than $1 \mathrm{~cm}$ in mucosal hyperplasia (mucocele), with the hyperplasia in epithelial cells. Villous adenomatous changes and, to some degree, cellular atypia have occurred in the epithelial cells of mucinous cystadenoma which is the most often encountered form in the literature. Cystadenocarcinoma is the most prognostically dangerous form of appendiceal mucinous neoplasms and a malignant tumor derived from the peritoneal glandular stromal cells or epithelial cells. (11). We observed simple mucocele in four patients $(30.7 \%)$, mucosal hyperplasia in three $(23.2 \%)$, mucinous cystadenoma in four $(30.7 \%)$, and mucinous cystadenocarcinoma in two (15.4\%). Incidence of mucinous cystadenoma was higher than that of other types.

The clinical presentation of mucocele of the appendix is usually non-specific. Abdominal pain is the most common symptom of symptomatic patients. Other symptoms include abdominal mass, weight loss, nausea, vomiting, changes in bowel habits, unexplained anemia, obstipation, and lower gastrointestinal system bleeding (12). A large number of patients often admit to emergency service with one or more of these symptoms. In our study, while 11 patients were admitted to emergency service, other two patients admitted electively to the outpatient clinic. Abdominal pain, one of the most common symptoms, was present in 11 patients (84.5\%), abdominal mass in one $(7.75 \%)$, and lower gastrointestinal system bleeding in one (7.75\%). Appendiceal mucocele may present as spontaneous rupture of mucocele along with acute appendicitis, leading to PP syndrome. This PP syndrome following the rupture may manifest through nonspecific symptoms such as abdominal hernia and ovarian mass.

Laboratory investigation of patients with appendiceal mucinous tumors shows that leukocytosis and an increase in CRP values for these tumors are not as high as those in acute appendicitis. Leukocytosis was present in five (42\%) and normocytosis (58\%) in seven of 12 patients with measured values. Data on CRP (C-reactive protein) value of six patients could not be obtained from the medical records, but there was an increase in this value for six (86\%) out of the remaining seven patients.

Preoperative diagnosis is thought to be an important factor for the determination of surgical management and the extension of surgery, but preoperative diagnosis is generally difficult (8). Although a mucocele may be diagnosed preoperatively with abdominal USG, CT, or MRI, diagnosis is generally made intraoperatively due to macroscopic appearance and a final diagnosis can only be reached after histopathological examination of the specimen $(8,13,14)$. However, preoperative diagnosis is possible as a preliminary diagnosis when cystic dilation of the appendix, mural calcification of the appendix wall, luminal diameter greater than $15 \mathrm{~mm}$, and lack of appendicolith are observed on imaging studies (13). In this study, CT was performed in two patients, MRI in one patient, and CT and USG in two patients. The mucocele can be seen as a well-encapsulated, thin-walled, round cystic mass with abdominal CT, and also calcification can be seen in about half of the cases. Abdominal USG reveals an encapsulated cystic lesion associated with the cecal wall. An image is formed in varying echoes depending on the density of mucin within the cyst. Multiple echogenic layers give it an onion skin appearance in some patients, suggesting that this appearance is pathognomonic for mucocele. Nodular appearance in the cyst wall may increase the likelihood of developing cystadenocarcinoma. Although malignancy is rarely seen in a diameter of $2 \mathrm{~cm}$ or less, the possibility of developing malignancy increases if the diameter is $6 \mathrm{~cm}$ or larger. Macroscopic examination of 12 patients' appendix from pathology records showed that the average diameter was $23.5 \mathrm{~mm}$ (ranging from $5 \mathrm{~mm}$ to $50 \mathrm{~mm}$ ), and the average length was $62 \mathrm{~mm}$ (varying from $35 \mathrm{~mm}$ to $140 \mathrm{~mm}$ ). The average diameter of the appendix of malignancy-detected patients was 30 $\mathrm{mm}$ and the average length was $120 \mathrm{~mm}$. Abdominal ascites is a non-specific finding in PP syndrome. Mucin deposits may localize in natural spaces, liver, and spleen within the abdominal cavity. In this study, epithelial cells were identified in the mucin deposits of only one out of four patients with a detection of periappendiceal mucin deposits.

The key principle in the surgical treatment of appendiceal mucinous toumors is the necessity of excising largely all mesoappendix including appendix and its lymph nodes, which can vary by associated benign or malignant pathology (8). To determine the surgical extension, the base of the appendix should be checked during surgery. Positive margins and difficulties in closing the appendiceal stump, call for a more extensive surgery such as cecectomy. When the luminal diameter of the appendix is larger than $2 \mathrm{~cm}$, in case of extension beyond the appendix such as lymph node metastasis and PP syndrome, and in case of cystadenocarcinoma based on frozen section examination, right hemicolectomy should be the choice for extensive surgery (13). Switching to open surgery on detection of mucocele during laparoscopic approaches is extremely important in order to explore all spaces in the peritoneal cavity and assure that the appendix wall remains intact and does not develop PP syndrome, which is considered to be malignant as a result of a rupture that may occur $(4,5)$. However, the experience of the surgical team in laparoscopy is the principal determining factor for proceeding laparoscopically $(8,13)$.

In this study, periappendiceal mucin deposits were detected in four patients intraoperatively. Right hemicolectomy was performed in the same session for two of these patients whose histopathological examination was reported as cystadenocarcinoma and for other two, in the early period after appendectomy. Partial cecum resection together with appendectomy was performed for one patient with giant benign mucinous cystadenoma based on the result of frozen section examination. Seven patients underwent wide mesoappendix excision along with appendectomy. The root of the appendix should be examined and excised carefully. While examining the abdominal cavities, if any mucin deposit is noticed, sufficient amount of sample should be sent for cytological examination and intra-abdominal parts should be washed with plenty of physiological saline solution. 
Rupture of mucocele and discharge of mucus and epithelial cells in the abdominal and peritoneal cavity are associated with poor prognosis due to the risk of PP syndrome or appendiceal mucinous carcinomatosis. Treatment is more complicated in PP syndrome where diffuse mucin deposits and mucinous implants are found on omental and peritoneal surfaces and in the abdominal cavity. The basic principle of the surgery in case of PP is that as much tumor as possible should be removed from the relevant region since development of symptomatic recurrences including remote and nodal metastases may take years because of the slow progression of the disease (14). Removal of all microscopic foci and omentum is required. Also in female patients, routine appendectomy and bilateral salpingo-oophorectomy along with hysterectomy are required. Results of $\mathrm{R} 0$ and $\mathrm{R} 1$ resections are better than those of R2 when compared in terms of survival $(14,15)$. In these patient groups, hyperthermic intraperitoneal chemotherapy together with cytoreductive surgery is a standard practice at many centers $(16,17)$. Repetitive operations should be performed in case of any recurrences.

\section{CONCLUSION}

As a consequence, preoperative diagnosis of mucocele of the appendix is difficult, so when a mass like appearance is seen on imaging studies, it should be kept in mind that with a high possibility it is a kind of mucocele and carries a risk of perforation which can cause PP. Further, it should be kept in mind that solid organ tumors may accompany mucocele, and PP risk lasts for a long term postoperatively. Therefore, it is reasonable to explore thoroughly during operation and periodically follow-up patients after discharge. The sufficient and required treatment for mucocele is simple appendectomy with negative margins, but cecum resection or a right hemicolectomy may be necessary depending on the size and location. During the surgery, maximum care should be taken to avoid intraperitoneal rupture of a mucocele because of the risk of PP.

Ethics Committee Approval: Ethics committee approval was received for this study from the ethics committee of Kahramanmaraş Sütçü İmam University (Date: 04/20/2016, decision no: 131/10).

Informed Consent: Informed consent was not received due to the retrospective nature of the study.

Peer-review: Externally peer-reviewed.

Author Contributions: Concept - M.S.; Design - A.E.; Supervision I.T.K.; Resource - A.E.; Materials - I.T.K.; Data Collection and/or Processing - M.S.; Analysis and/or Interpretation - I.T.K.; Literature Search - A.E.; Writing Manuscript - A.E.; Critical Reviews - A.E.

Conflict of Interest: No conflict of interest was declared by the authors.

Financial Disclosure: The authors declared that this study has received no financial support.

\section{REFERENCES}

1. Woodruff R, Mc Donald J. Benign and malignant cystic tumors of the appendix. Surg Gynecol Obstet 1940; 71: 751-755.

2. Emre A, Akbulut S, Bozdag Z, Yilmaz M, Kanlioz M, Emre R, et al. Routine histopathologic examination of appendectomy specimens: retrospective analysis of 1255 patients. Int Surg 2013; 98 : 354-362. [CrossRef]

3. Yilmaz M, Akbulut S, Kutluturk K, Sahin N, Arabaci E, Ara C, et al. Unusual histopathological findings in appendectomy specimens from patients with suspected acute appendicitis. World J Gastroenterol 2013; 19: 4015-4022. [CrossRef]

4. Dhage-Ivatury $\mathrm{S}$, Sugarbaker $\mathrm{PH}$. Update on the surgical approach to mucocele of the appendix. J Am Coll Surg 2006; 202: 680-684. [CrossRef]

5. Rokitansky C. Handbuch der Pathologischen Anatomie. Braumüller und Seidel, Wien; 1842- 1846.

6. Akbulut S, Tas M, Sogutcu N, Arikanoglu Z, Basbug M, Ulku A, et al. Unusual histopathological findings in appendectomy specimens: a retrospective analysis and literature review. World J Gastroenterol 2011; 17: 1961-1970. [CrossRef]

7. Tărcoveanu E, Vasilescu A, Hee RV, Moldovanu R, Ursulescu C, Ciobanu D, et al. Appendicular Mucocele: Possibilities and Limits of Laparoscopy. Brief Series and Review of the Literature. Chirurgia (Bucur) 2015; 110: 530-537.

8. Kılıç MÖ, İnan A, Bozer M. Four mucinous cystadenoma of the appendix treated by different approaches. Turk J Surg 2014; 30: 97-99. [CrossRef]

9. Higa E, Rosai J, Pizzimbono CA, Wise L. Mucosal hyperplasia, mucinous cystadenoma, and mucinous cystadenocarcinoma of the appendix. A re-evaluation of appendiceal "mucocele". Cancer 1973; 32: 1525-1541. [CrossRef]

10. Pai RK, Longacre TA. Pseudomyxoma peritonei syndrome: classification of appendiceal mucinous tumours. Cancer Treat Res 2007; 134: 71-107. [CrossRef]

11. Pai RK, Longacre TA. Appendiceal mucinous tumors and pseudomyxoma peritonei: histologic features, diagnostic problems, and proposed classification. Adv Anat Pathol 2005; 12: 291-311. [CrossRef]

12. Rymer B, Forsythe RO, Husada G. Mucocoele and mucinous tumours of the appendix: A review of the literature. Int J Surg 2015; 18: 132-135. [CrossRef]

13. Malya FU, Hasbahceci M, Serter A, Cipe G, Karatepe O, Kocakoc E, et al. Appendiceal mucocele: clinical and imaging features of 14 cases. Chirurgia (Bucur) 2014; 109: 788-793.

14. Stocchi L, Wolff BG, Larson DR, Harrington JR. Surgical Treatment of Appendiceal Mucocele. Arch Surg 2003; 138: 585-590. [CrossRef]

15. Gough DB, Donohue JH, Schutt AJ, Gonchoroff N, Goellner JR, Wilson TO, et al. Pseudomyxoma peritonei. Long-term patient survival with an aggressive regional approach. Ann Surg 1994; 219: 112-119. [CrossRef]

16. Duckworth KE, McQuellon RP, Russell GB, Cashwell CS, Shen P, Stewart JH 4th, et al. Patient rated outcomes and survivorship following cytoreductive surgery plus hyperthermic intraperitoneal chemotherapy (CS+HIPEC). J Surg Oncol 2012; 106: 376-380. [CrossRef]

17. Cummins KA, Russell GB, Votanopoulos KI, Shen P, Stewart JH, Levine EA. Peritoneal dissemination from high-grade appendiceal cancer treated with cytoreductive surgery (CRS) and hyperthermic intraperitoneal chemotherapy (HIPEC). J Gastrointest Oncol 2016; 7: 3-9. 